\title{
Effect of pregnancy and stage of lactation on energy processes in isolated blood cells of dairy cows
}

\author{
Bogdan Dębski ${ }^{1}$, Tadeusz Nowicki ${ }^{2}$, Wojciech Zalewski ${ }^{3}$, \\ Agnieszka Bartoszewicz ${ }^{3}$, Jan Twardoń ${ }^{3}$ \\ ${ }^{1}$ Department of Physiological Sciences, Faculty of Veterinary Medicine, \\ Warsaw University of Life Sciences, 02-766 Warsaw, Poland \\ ${ }^{2}$ Military University of Technology, 00-908 Warsaw, Poland \\ ${ }^{3}$ Department of Reproduction and Clinic of Farm Animals, Faculty of Veterinary Medicine, \\ Wroclaw University of Environmental and Life Sciences, 50-375 Wroclaw, Poland \\ jan.twardon@up.wroc.pl
}

Received: April 14, 2016 Accepted: May 10, 2017

\begin{abstract}
Introduction: The transition period is the most challenging time for dairy cattle, which is characterised not only by negative energy balance but also by fatty tissue mobilisation. Material and Methods: The efficiency of energy pathways, $\beta$-oxidation in $\mathrm{WBC}$ and glycolysis in RBC (based on deoxyglucose transmembrane transport) were estimated. Insulin in blood plasma was determined using ELISA. Results: After calving and up to one month after delivery, a significant drop in blood plasma level was noticed, simultaneously with a rise in $\beta$-oxidation from $18.93 \pm 3.64$ to $30.32 \pm 5.28 \mathrm{pmol} / \mathrm{min} / \mathrm{mg}$ protein in WBC. A strong negative correlation between these two indices $(r=-0.68)$ was found. During the period of transition to lactation an increase in glucose cross-membrane transportation from $41.44 \pm 4.92$ to $50.49 \pm 6.41 \mu \mathrm{mol} / \mathrm{h} / \mathrm{g} \mathrm{Hb}$ was observed. A strong positive correlation between glucose transportation in RBC and $\beta$-oxidation in WBC $(r=0.71)$ was noticed. These data are in agreement with results of studies on dairy cows using liver slices from dairy cows in late pregnancy and different stages of lactation, in which changes in gene expression were analysed. Conclusion: It seems that measuring fatty acids oxidation and glycolysis using isolated blood cells may be an adequate and relatively simple method for energy state analysis to estimate the state of dairy cow metabolism and animal health.
\end{abstract}

Keywords: dairy cows, energetic metabolism, perinatal period, lactation.

\section{Introduction}

During the transition period cows undergo many physiological changes leading to negative energy balance (NEB). High-yielding dairy cows enter a state of NEB just before calving and it may take up to 20 weeks to regain a positive energy balance (24). NEB is caused by a rapid rise in energy requirement, which is for milk production, and is connected with a decrease in dry matter intake taking place a week before parturition $(5,15)$. In early lactation in high-producing cows, the appearance of NEB leads to the overproduction of free fatty ac ids (FFA) and their release into the blood and transfer to the liver. An increased rate of lipolysis causes overproduction of FFA and at the same time the rate of glycolysis is diminished. An increase in FFA in blood plasma was observed, as well as a fall of blood glucose concentration in dairy cows in early lactation (23). The basic problem during ketosis is glucose deficiency, caused firstly by the increasing needs of the developing calf, and subsequently after parturition by the needs of lactose and milk fat production: to synthesise 11 of milk ca. $80 \mathrm{~g}$ of glucose is needed. To cover these rapidly increased energy requirements, lipolysis is stimulated in muscles and liver, but to metabolise the high amount of FFA in the $\beta$-oxidation process, also a high amount of oxaloacetate is needed, which is the carbon carrier of the tricarboxylic acid cycle. However, in such circumstances a part of oxaloacetate is hydrogenated to malate from which glucose is synthesised. The limiting factor for proper FFA oxidation is likely oxaloacetate. Deficiency of this metabolic intermediate slows down the TCA cycle and would favour the accumulation of ketone bodies (acetone, acetoacetate, and $\beta$-hydroxy- 
butyrate). Ketone bodies present in exhaled air have an easy-to-detect smell, usually described as fruity, sweet, or acetone-like. The first sign of ketosis is the decline of appetite (cows often consume grass and hay but do not eat grain or silage) connected with a decrease in milk yield. Some cows develop neurological signs including movement incoordination, aimless wandering, salivation, and sometimes aggressive behaviour. Very often the first signs of ketosis occur within two to three weeks after calving, but cows fed component feed and housed in individual stalls appear to develop ketosis three to six weeks after parturition. The studies by Duffield et al. (9) show that in some herds the incidence of ketosis may reach $40 \%-60 \%$ of cows. Also Knob and Cernescu (14) suggest that at the beginning of lactation, at least $50 \%$ of all dairy cows have a temporary period of subclinical ketosis.

To elucidate the energy status of dairy cows, estimation of glycolysis and $\beta$-oxidation efficacy was performed and insulin concentration in blood plasma was measured. In separated red blood cells (RBC) crossmembrane deoxyglucose transportation was used as a measure of glucose uptake and in isolated leukocytes the process of $\beta$-oxidation was estimated using tritiated palmitic acid.

The aim of this study was to estimate the energy metabolism in dairy cows in late pregnancy, early lactation, and one to three months after parturition using separated blood cells.

\section{Material and Methods}

Experimental animals. The study was performed on 40 clinically healthy Holstein-Friesian dairy cows chosen from three dairy farms. The farms were located in southwest Poland and husbanded 200-300 cows fed a TMR diet and housed in open free-stall barns with concrete floors covered with straw and rubber mats. Lactating cows were milked twice a day in a parallel parlour system with eight milking units. The duration of lactation periods was on average $300 \pm 15 \mathrm{~d}$ and the milk yield calculated per lactating cow was 8,000-9,000 1 .

Blood sampling. Blood samples were taken from the jugular vein and collected in tubes containing EDTA. The appointed stages for sampling were before parturition, during the first month after calving, and one to three months after parturition. The samples were placed on ice and centrifuged for $10 \mathrm{~min}$ at 3,000 g. The plasma obtained was stored at $-80^{\circ} \mathrm{C}$ until insulin analysis was performed.

Analysis. Erythrocytes (RBC) and leukocytes (WBC) were separated by centrifugation of whole blood on the gradient of HISTOPAQUE-1077. RBC formed a pellet, whereas WBC were located on the HISTOPAQUE/plasma border. The cells were washed twice with cold PBS and resuspended in medium equal to the initial volume of blood.

Insulin was assayed using an Alpco Diagnostics ELISA-kit for bovine insulin (USA). The method is a sandwich-type immunoassay using mouse monoclonal antibodies specific for bovine insulin. The sensitivity of the assay was $0.1 \mathrm{ng} / \mathrm{ml}$ and within-run variation was $3.5 \%$.

The glycolysis value in RBC was evaluated by estimation of glucose transport across cell membranes. Uptake of $\left({ }^{3} \mathrm{H}\right)$ deoxyglucose in erythrocytes incubated for $10 \mathrm{~min}$ in HEPES solution was determined using the method described by Lee et al. (17) with slight modification (7). After incubation of the cells (15 min) with $0.1 \mu \mathrm{Ci}$ 2-deoxyglucose (Moravek Biochemicals, USA), RBC were centrifuged for $10 \mathrm{~min}$ at $1,000 \mathrm{~g}$, then the pellet was washed with cold physiological saline, dissolved in $2 \mathrm{mmol} \mathrm{NaOH}$, and counted in a Packard TriCarb scintillation counter (PerkinElmer, USA). Results were expressed as $\mu \mathrm{mol} \mathrm{Gl} / \mathrm{g}$ of haemoglobin per $1 \mathrm{~h}$. Haemoglobin was estimated by Drabkin's cyanmethaemoglobin method.

Fatty acid degradation was examined in WBC using the method of Manning et al. (18) and the modification of Kuryl et al. (16). The cells were incubated for $1 \mathrm{~h}$ with $0.1 \mu \mathrm{Ci}$ of $\left(9,10-{ }^{3} \mathrm{H}\right)$ palmitic acid (Moravek Biochemicals, USA) and after incubation were precipitated with $10 \%$ TCA and centrifuged for $10 \mathrm{~min}$ at 2,000 g. Supernatant was collected, alkalised, and passed through a Bio-Rad AG-1 X8 ionic exchange resin column (Bio-Rad, USA). Effluent containing tritiated water was counted in the Packard TriCarb scintillation counter. Results were expressed as pmol of palmitic acid decomposed per mg of WBC protein during $1 \mathrm{~h}$.

Statistics. Statistical analysis was performed using Statistica software (Statsoft, Poland), adhering to the ANOVA method. The possible impact of certain independent variables (factors) on the value of the dependent variable (the variable being tested and measured) was checked. The independent variable in statistical analysis was the moment of sampling. Fisher's Least Significance Difference (LSD) and the F-ratio (obtained in an F-test) for different groups were calculated. The F-ratio expresses the ratio of variability between groups to variability within groups. The larger the F-value is, the more certain is the difference between groups. The Pearson correlation coefficient between the obtained values was also calculated.

\section{Results}

The results of the study and statistical values of LSD are presented in Table 1. The lowest level of $\beta$-oxidation in WBC was noticed in dairy cows before parturition. In these cells a significant rise in efficacy of this pathway was observed after calving. A similar trend for glycolysis was found in RBC. An increase in acrossmembrane transport of deoxy-glucose was also detected in cells isolated from blood taken from cows after calving (compared to the prepartum period). In cows one to three months after parturition both $\beta$-oxidation and glycolysis were slightly lower, but statistical differences were still significant. The insulin concentration was the 
Table 1. Values of $\beta$-oxidation in leukocytes, glucose transport across red blood cells and serum insulin concentrations in dairy cows before and after parturition. $\mathrm{n}=40$

\begin{tabular}{|c|c|c|c|c|c|}
\hline \multirow[b]{2}{*}{ Indices } & \multicolumn{3}{|c|}{ Blood sampling } & \multicolumn{2}{|c|}{ Statistics } \\
\hline & $\begin{array}{l}0-1 \text { month } \\
\text { before } \\
\text { parturition }\end{array}$ & $\begin{array}{l}0-1 \text { month } \\
\text { after parturition }\end{array}$ & $\begin{array}{l}1-3 \text { months } \\
\text { after parturition }\end{array}$ & $\begin{array}{l}\text { LSD } \\
\text { value }\end{array}$ & $\begin{array}{l}\text { F-test } \\
\text { value }\end{array}$ \\
\hline $\begin{array}{l}\beta \text {-oxidation } \\
(\mathrm{pmol} / \mathrm{min} / \mathrm{mg} \text { protein })\end{array}$ & $18.93 \pm 3.64^{\mathrm{a}}$ & $30.32 \pm 5.28^{b}$ & $28.63 \pm 4.64^{b}$ & 1.98 & 72.4 \\
\hline $\begin{array}{l}\text { Glucose transport } \\
(\mu \mathrm{mol} / \mathrm{h} / \mathrm{g} \mathrm{Hb})\end{array}$ & $41.44 \pm 4.92^{\mathrm{a}}$ & $50.49 \pm 6.41^{\mathrm{c}}$ & $47.17 \pm 5.99^{b}$ & 2.57 & 24.9 \\
\hline $\begin{array}{l}\text { Insulin } \\
(\mu \mathrm{g} / \mathrm{l})\end{array}$ & $1.36 \pm 0.21^{\mathrm{c}}$ & $0.85 \pm 0.17^{\mathrm{a}}$ & $1.25 \pm 0.15^{\mathrm{b}}$ & 0.08 & 86.6 \\
\hline
\end{tabular}

Means \pm SD

Means in rows not sharing the same superscript letter differ at $\mathrm{p} \leq 0.05$

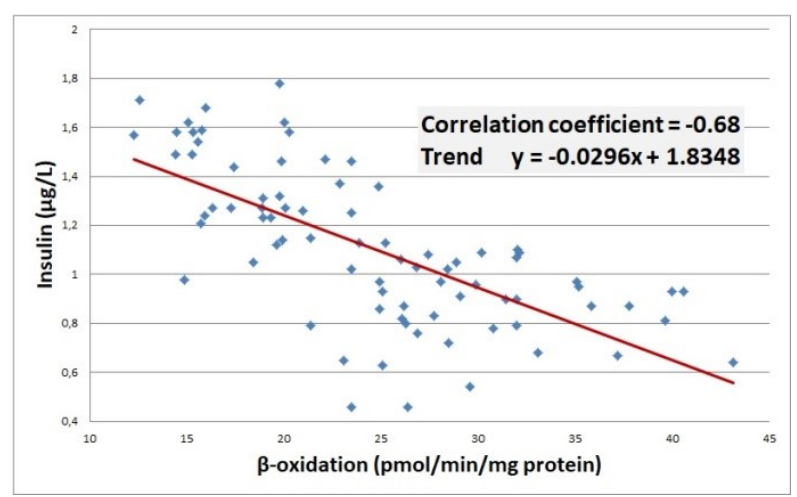

Fig. 1. Dependence between insulin concentration in blood plasma and $\beta$-oxidation in $\mathrm{WBC}$ of cows in one month before calving to one month postpartum

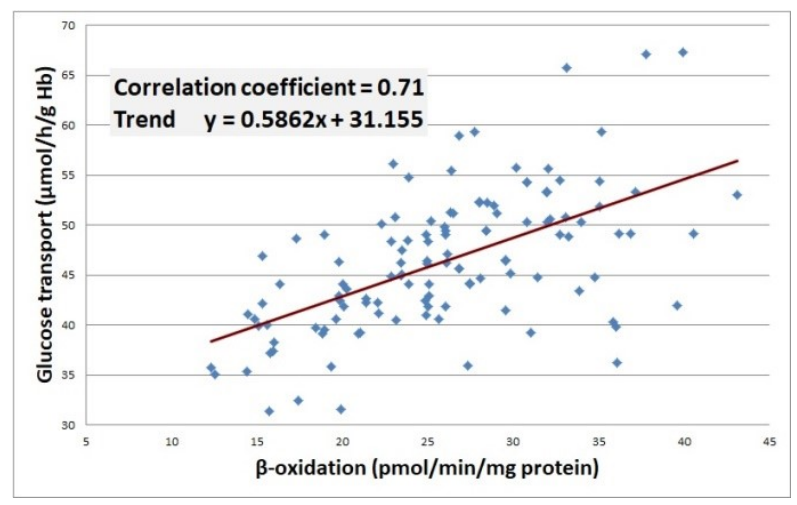

Fig. 2. Dependence between glucose transmembrane transport in $\mathrm{RBC}$ and $\beta$-oxidation in WBC of cows in one month before calving to one month postpartum

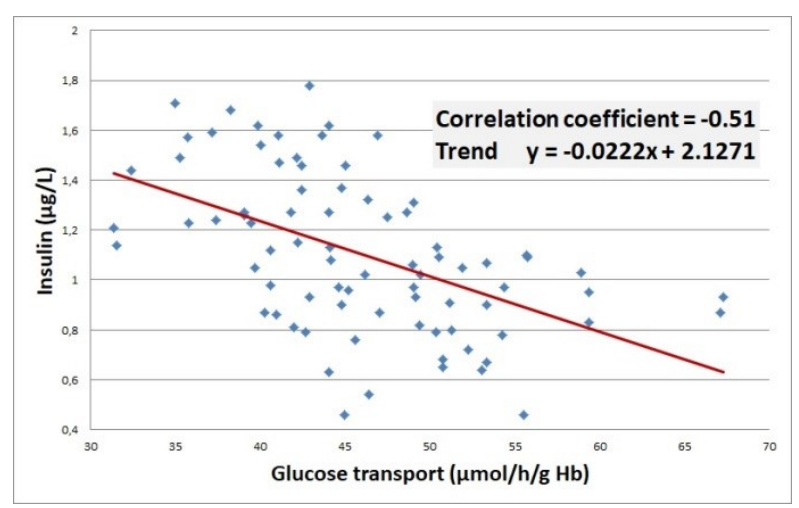

Fig. 3. Dependence between insulin concentration in blood plasma and glucose transmembrane transport in RBC of cows in one month before calving to one month postpartum

highest at prepartum and a significant drop was observed in the first month after calving. The statistical relationship between variables is given in Figs 1-3. Correlatedness between groups of results was lower by about $20 \%$ when values obtained in the period one to three months after parturition were included. For the calculation of the correlation coefficient only the results obtained within the period of one month before birth to one month after calving were used. The linear trend of this correlation is shown in Fig. 1. A strong negative correlation $(r=-0.68)$ was observed between $\beta$-oxidation in leukocytes and the insulin concentration in blood plasma (Fig. 1). The highest positive correlation coefficient $(\mathrm{r}=0.71)$ was found between $\beta$-oxidation of fatty acids in leukocytes and glucose transport through the cell membrane (Fig. 2). A lower correlation $(\mathrm{r}=-0.51)$ was observed between glucose transportation in RBC and plasma insulin concentration (Fig. 3).

\section{Discussion}

In dairy cows energy metabolism during late pregnancy and the month after calving plays a crucial role. To evaluate the influence of pregnancy and lactation on the energy metabolism of dairy cows we chose the determination of $\beta$-oxidation of palmitic acid and transmembrane transport of glucose (as a measure of glycolysis). The main energy production takes place in the liver and muscles, but for the isolation of cells from these organs the use of proteases would be necessary, which is time-consuming and involves a great risk that the procedure would significantly affect cell metabolism. It was the reason why we decided to estimate the efficacy of energy pathways in RBC and WBC. Schaff et al. (21) found that dairy cow muscle samples reveal an increased expression of genes involved in fatty acid transport and oxidation after parturition. It is in agreement with the hepatic oxidation theory, showing increased hepatic fatty acid oxidation during early lactation. However, the increased oxidation of FA may prolong the depression of feed intake (2). Perdomo et al. (19) suggested that increased $\beta$-oxidation in muscles exerts an insulin-sensitising effect caused by intramuscular accumulation of FA derivate. The effect of $\beta$-oxidation stimulation postpartum was also observed in this experiment in WBC of dairy cows (Table 1). We observed $60 \%$ higher $\beta$-oxidation in early lactation 
compared with the efficiency of this pathway in cows before calving. Simultaneously a fall in plasma insulin is observed which causes a strong negative correlation between the rate of $\beta$-oxidation and blood plasma insulin concentration (Fig. 1). Liver uptake of nonestrified fatty acids (NEFA) is proportional to their concentration in blood, which is the highest in cows' milk during the lactation period in days 3-30. Abuelo et al. (1) observed that the rise of NEFA in early lactation was much higher in organically managed cows comparing with those conventionally managed. In the liver NEFA may be used for energy supply via $\beta$-oxidation, metabolised to ketones or re-estrificated to triacylglycerols (25). However, transport of triacylglycerols from the liver to muscles by low density lipoproteins is not very efficient and it may lead to hepatic triacylglycerol accumulation. This accumulation is observed in early lactation and causes the major metabolic disorder called "fatty liver". Cows suffering fatty liver have increased susceptibility to infectious diseases and fertility problems (26). Currently ultrasonic and proteomic techniques may be helpful in detection of this metabolic disorder in dairy cattle (5). Determination of liver functionality index and/or rumination time can also be used to identify cows at a greater risk of developing diseases (6). We noticed a strong positive correlation of $\beta$-oxidation with glucose transmembrane transportation (as a glycolysis rate marker) (Fig. 2) showing significant increase in energy production at the beginning of lactation.

The concentration of glucose and insulin in dairy cows were the lowest after calving and in early lactation, then they increased steadily $(1,13)$. However, in highproducing cattle, the high milk yield is related to the lower glucose and insulin concentrations (11). In early lactation we observed a significant drop of insulin concentration in plasma from $1.36 \pm 0.21$ to $0.85 \pm 0.17 \mu \mathrm{g} / \mathrm{L}$ (Table 1). However, the study of Beck-Nielsen et al. (4) demonstrated a decrease in insulin binding to leukocytes of pregnant women. It is possible that high plasma insulin concentration might not be so effective. In dairy cows the lowering of insulin level following calving seems to be one of the adaptation changes occurring around calving time to support the start of lactation (20). Lower plasma insulin concentration and diminished glucose uptake by insulin-responsive peripheral tissues cause more glucose to be utilised by the insulinindependent mammary gland (3). In period of one month before calving to one month postpartum we observed a negative correlation of transmembrane glucose transport in RBC with plasma insulin concentration (Fig. 3). The findings of Terao et al. (25) suggest low insulin sensitivity in peripheral tissues in early lactation in cows. Significant variation of peripheral tissue sensitivity to insulin and of insulin to glucose infusions was found among cattle breeds (12).

Seider and Kim (22), who estimated transport of a glucose analogue (3-O-methyl-glucose), found that bovine RBC exhibit a comparatively low glycolytic rate, which may be stimulated by different nucleosides and nucleotides, e.g. inosine or adenosine. It was shown that $2-3 \mu \mathrm{mol} / \mathrm{mL}$ of lactate is formed in cows' RBC per hour (13). Glucose transmembrane transport is an insulin-independent mechanism of facilitated diffusion through glucose transporters (GLUT-1) (10). Although glucose transport is insulin-independent we observed a moderate negative correlation of RBC glucose transmembrane transport with plasma insulin concentration (Fig. 3). In glycolysis an energyconversion pathway ATP is produced and reduction of $\mathrm{NAD}^{+}$occurs. The pentose phosphate shunt, parallel to glycolysis, generates NADPH ( $\beta$-nicotinamide adenine dinucleotide 2'-phosphate) which is necessary for glutathione reduction. Adult RBC do not possess any mitochondria so anaerobic glycolysis supplies only two molecules of ATP per molecule of glucose utilised. In liver slices of high-producing dairy cows it was found that insulin tended to decrease palmitate oxidation, but this effect was diminished by carnitine (8).

Elevated lipolysis and high energy production occurring in the transition period in dairy cattle have been shown to be associated with increased risk of disorders and reduced milk yield. The evaluation of the energy metabolism of cows using isolated blood cells during the transition period and early lactation may be a significant step towards recognising high-risk cows and a good method of improving herd management.

Conflict of Interests Statement: The authors declare that there is no conflict of interests regarding the publication of this article.

Financial Disclosure Statement: The work was supported by Grant for Scientific Research from the National Science Centre (NN308576640).

Animal Rights Statement: None required.

\section{References}

1. Abuelo A., Hernandez J., Benedito J.L., Castello C.: A comparative study of the metabolic profile, insulin sensitivity and inflammatory response between organically and conventionally managed dairy cattle during the periparturient period. Animal 2014, 8, 1516-1525.

2. Allen M.S., Bradford B.J., Oba M.: The hepatic oxidation theory of the control of feed intake and its application to ruminant. J Anim Sci 2009, 87, 3317-3334.

3. Bauman D.E., Elliot J.M.: Control of nutrient partitioning in lactating ruminant. In: Biochemistry of lactation, edited by T.B. Mephan, Elsevier Science Publisher, Amsterdam, 1983, pp. $437-468$.

4. Beck-Nielsen H., Kuhl C., Pedersen O., Bjerre Christensen C., Nielsen T.T., Klebe J.G.: Decreased insulin binding to monocytes from normal pregnant women. J Clin Endocrinol 1979, 49, $810-814$.

5. Bobe G., Young J.W., Beitz D.C.: Pathology, etiology, prevention, and treatment of fatty liver in dairy cows. J Dairy Sci 2004, 87, 3105-3124.

6. Calamari L., Soriani N., Panella G., Petrera F., Minuti A., Trevisi E.: Rumination time around calving: an early signal to detect cows at greater risk of disease. J Dairy Sci 2013, 97, 3635-3647. 
7. Dębski B., Kuryl T., Gralak M.A., Pierzynowska J., Drywień M.: Effect of inulin and oligofructose of the diet on rats suffering thiamine deficiency. Anim Physiol Anim Nutr 2011, 95, 335-342.

8. Drackley J.K., Beitz D.C., Young J.W.: Regulation of in vitro palmitate oxidation in liver from dairy cows during early lactation. J Dairy Sci 1991, 74, 1884-1892.

9. Duffield T.F., Sandals D., Leslie K.E., Lissemore K., McBride B.W., Lumsden J.H., Dick P., Bagg R.: Efficacy of monensin for the prevention of subclinical ketosis in lactating dairy cows. J Dairy Sci 1998, 81, 2866-2873.

10. Hajjawi O.S.: Glucose transport in human red blood cells. Am J Biomed Life Sci 2013, 1, 44-52.

11. Herbein J.H., Aiello R.J., Eckler L.I., Pearson R.E., Akers R.M.: Glucagon, insulin, growth hormone, and glucose concentration in blood plasma of lactating dairy cows. J Dairy Sci 1985, 68, $320-325$.

12. Jaakson H., Ling K., Samarutel J., Ilves A., Kaar T., Kart O.: Field trial on glucose-induced insulin and metabolite responses in Estonian Holstein and Estonian Red dairy cows in two herds. Acta Vet Scand 2010, 52, 1, 1-7.

13. Kim H.D.: Cow red blood cells III. Postnatal adaptation of energy metabolism in the calf red blood cells. BBA 1979, 588, 44-54.

14. Knob R., Cernescu H.: Effects of negative energy balance on reproduction in dairy cows. Lucrari Stintifice Med Vet (Timisoara) 2009, 62, 198-205.

15. Kuhla B., Nurnberg G., Albrecht D., Gors S., Hammon H.M., Metges C.C.: Involvement of skeletal muscle, glycogen, and fat metabolism in the adaptation on early lactation of dairy cows. J Proteome Res 2011, 10, 4252-4262.

16. Kuryl T., Adamowicz M., Dębski B., Bertrandt J., Martynik K.: Degradation of $(9,10)-{ }^{3} \mathrm{H}-$ myristic acid by lymphocytes. Screening test of inherited disorders of activation, transport, and mitochondrial oxidation of fatty acids. Ateroskleroza 2001, 5, 23-27.

17. Lee D.N., Yen H.T., Shen T.F., Chen B.J.: Chromium-induced glucose uptake, superoxide anion production and phagocytosis in cultured pulmonary alveolar macrophages of weaning pigs. Biol Trace Elem Res 2000, 77, 53-64.
18. Manning N.J., Olpin S.E., Pollitt R.J., Webley J.: A comparison of $\left(9,10-{ }^{3} \mathrm{H}\right)$ palmitic and $\left(9,10-{ }^{3} \mathrm{H}\right)$ myristic acid for the detection of defects of fatty acid oxidation in intact cultured fibroblast. J Inherited Metab Dis 1990, 13, 58-68.

19. Perdomo G., Commerford S.R., Richard A.M., Adams S.H., Corkey B.F., O’Doherty R.M., Brown N.F.: Increased $\beta$-oxidation in muscle cells enhanced insulin-stimulated glucose metabolism and protects against fatty acids-induced insulin resistance despite intramyocellular lipid accumulation. J Biol Chem 2004, 279, 27177-27186.

20. Sano H., Nakai M., Kondo T., Terashima Y.: Insulin responsiveness to glucose and tissue responsiveness to insulin in lactating, pregnant, and nonpregnant, nonlactating beef cows. J Anim Sci 1990, 69, 1122-1127.

21. Schaff C., Borner S., Hacke S., Kautzsch U., Sauerwein H., Spachmann S.K., Schweigel-Rontgen M., Hammon H.M., Kuhla B.: Increased muscle fatty acids oxidation in dairy cows with intensive body fat mobilization during early lactation. J Dairy Sci 2013, 96, 6449-6460.

22. Seider M.J., Kim H.D.: Cow red blood cells. I. Effect of purines, pyrimidines, and nucleosides in bovine red cell glycolysis. Am J Physiol 1979, 236, 255-261.

23. Studzinski T., Filar J., Czarnecki A., Madej E.: Hormonal and metabolic adaptations to parturient and early lactation periods in dairy cows. Med Weter 2003, 59, 811-816.

24. Taylor V.J., Beever D.E., Watches D.C.: Physiological adaptations to milk production that affect fertility in high yielding dairy cows. Br Soc Anim Sci Occasional Publ 2003, vol. 29, Nottingham University Press, UK, pp. 37-71.

25. Terao H., Fujita M., Tsumagari A., Sugino T., Bungo T.: Insulin dynamics in transition dairy cows as revealed by intravenous tolerance testing. J Anim Vet Adv 2010, 9, 2333-2337.

26. Wensing T., Kruip T., Geelen M.J., Wentink G.H., van den Top A.M.: Postpartum fatty liver in high-producing dairy cows in practice and in animal studies. The connection with health, production and reproduction problems. Comp Haematol Int 1997, 7, 167-171. 